\section{(c) OPEN ACCESS}

\title{
The determinants of transitions into sheltered accommodation in later life in England and Wales
}

\author{
Athina Vlachantoni, ${ }^{1,2,3}$ Olga Maslovskaya, ${ }^{4}$ Maria Evandrou, ${ }^{1,2,3}$ Jane Falkingham ${ }^{1,3}$
}

\begin{abstract}
- Additional material is published online only. To view please visit the journal online (http://dx.doi.org/10.1136/jech2015-205462)

${ }^{1}$ EPSRC The Care Life Cycle Project, Southampton, UK ${ }^{2}$ Centre for Research on Ageing, Southampton, UK ${ }^{3}$ ESRC Centre for Population Change, Southampton, UK ${ }^{4}$ Southampton Statistical Sciences Research Institute (S3RI), University of Southampton, Southampton,
\end{abstract} UK

\section{Correspondence to} Dr Athina Vlachantoni, Faculty of Social, Human and Mathematical Sciences, Centre for Research on Ageing and ESRC Centre for Population Change, University of Southampton S017 1BJ, UK: A.Vlachantoni@soton.ac.uk

Received 7 January 2015 Revised 30 December 2015 Accepted 23 January 2016 Published Online First 19 February 2016

\begin{abstract}
Background Population ageing is a global challenge and understanding the dynamics of living arrangements in later life and their implications for the design of appropriate housing and long-term care is a critical policy issue. Existing research has focused on the study of transitions into residential care in the UK. This paper investigates transitions into sheltered accommodation among older people in England and Wales between 1993 and 2008.
\end{abstract}

Methods The study uses longitudinal data constructed from pooled observations across waves 2-18 of the British Household Panel Survey (BHPS) data, focusing on individuals aged 65 and over who lived in private housing at baseline and who were observed for two consecutive time points. A discrete-time logistic regression model was used to examine the association of transitioning into sheltered accommodation with a range of demographic, health and socioeconomic predictors.

Results Demographic (age, region), socioeconomic factors (housing tenure, having a washing machine) and contact with health professionals (number of visits to the general practitioner, start in use of health visitor) were significant determinants of an older person's move into sheltered accommodation.

Conclusions Transitions into sheltered accommodation are associated with a range of demographic and socioeconomic characteristics as well as service use but not with health. Such results indicate that this type of housing option may be accessible by individuals with relatively good health, but may be limited to those who are referred by gatekeepers. Policymakers could consider making such housing option available to everyone, as well as providing incentives for building lifecoursesensitive housing in the future.

\section{INTRODUCTION}

Across the developed world, the provision and financing of long-term care is increasingly becoming a central policy issue, challenging policymakers and governments alike. ${ }^{1}$ Changing dynamics in both the demographic composition of the population and the policy context in the area of long-term care, underpin the academic and policy debate in this area. ${ }^{2-4}$ Recent documents in the British policy landscape, such as the Dilnot Report, have emphasised the importance of appropriate housing to address the needs of older people, but also the need to develop further alternatives of long-term care for a growing number of home owners whose resources and expectations are different to previous generations of individuals. ${ }^{5}$ As such, understanding the pathways into different types of long-term care accommodation in later life is important from the perspective of both policymakers and individuals. This paper uses evidence from England and Wales in order to examine the underresearched topic of transitions into sheltered accommodation.

\section{Background}

Long-term care in the UK expanded through free services in the post-WWII period, before witnessing a period of financial austerity in the late 1970s and the 1980s. The introduction of the 1990 National Health Service (NHS) and Community Care Act simultaneously decreased the availability of residential and paid-for domiciliary care provided by local authorities, and tightened the conditions attached to its receipt. The Act's principal aim was to reduce the number of older people in institutional care, and to develop community care provision in order to enable older people to live in their own homes for as long as possible. During the same time, the unit costs of providing long-term care increased, resulting in a greater focus of decreasing statutory resources on older people who are most in need. ${ }^{7}$

Alongside the decrease in the overall level of social care provided, the literature has highlighted the increasing participation of the private sector in the 'mix' of long-term care and the concomitant decrease in the level of care provided by local authorities. ${ }^{8}$ Since the 1990 s, different types of long-term care have developed, responding to the policy aim of successive governments since the 1980 s to provide greater choice to users of longterm care. Different long-term care providers typically cater for different groups of the older population depending on individuals' health and social care needs, as well as key demographic and socioeconomic characteristics, such as their partnership status and ability to purchase privately provided care. ${ }^{9} 10$ Against this context, sheltered accommodation has developed as a key alternative within the mixed market of long-term care, is mainly but not exclusively for older people, and usually takes the form of a group of small bungalows or flats supervised by a Scheme Manager, who offers help and support in emergencies. Living in sheltered accommodation can provide greater independence for older people than other types of long-term care, and may be associated with relatively good health. At the same time, older people's socioeconomic status can also act as a critical determinant factor in terms of living in sheltered accommodation. This is because the current system of long-term care includes the assessment of an individual's care needs, living arrangements and their carers' circumstances by the local council, which can impact on the package of care an individual is offered and the contribution they are expected to make. ${ }^{11}$ 
International research on pathways into long-term care in later life has emphasised a combination of factors as predictors affecting such transitions. For example, Luppa et $a l^{12}$ conducted a review (36 articles) of the predictors of nursing home placement in later life in Canada, the USA, Europe, Australia and Hong Kong, and found that one's increased age, poor health, functional and cognitive impairment, prior placement in nursing care and a high number of medication prescriptions, were consistently strong predictors. Not having one's own home was also a strong predictor of entering nursing care, which was consistent with other studies of moving into institutional care ${ }^{13}$ and nursing or residential care in Northern Ireland. ${ }^{14}$ Qualitative research outside the British context has also explored the views of older people on the advantages and disadvantages of living in different types of accommodation, ${ }^{15}$ finding that older people in sheltered accommodation reported a higher level of perceived autonomy, sense of security and quality of life, compared with those living in private homes.

Within England and Wales, research on the determinants of moving into long-term care has tended to focus on residential care, usually including nursing homes, residential homes and long-stay hospital accommodation, but not on sheltered accommodation. Such previous research has explored the impact of demographic, socioeconomic and health factors on older people's likelihood of living in a long-term care institution. The literature focusing on demographic factors has emphasised characteristics such as living arrangements and having children as key predictors of moving into residential care, which may operate in opposite directions for men and women. For example, Breeze and Stafford ${ }^{16}$ analysed the Longitudinal Study (LS) and found that being single in 1971 and 1981 was a strong predictor for both women and men being in residential care in 1991; however, living alone was a strong predictor for men but not for women. Analysis of the British Household Panel Survey (BHPS) 1991-1998 by Evandrou et al ${ }^{17}$ showed that age and health measures were important predictors of institutionalisation in later life. Recent data on individuals aged 65 and over in 1991 who were still alive in 2001, analysed by Grundy and Jitlal, ${ }^{18}$ indicated that women carried a higher risk of moving into residential care than men, and that for both sexes, living alone in 1991 and being unmarried in 2001, as well as reporting a long-term illness, increased the likelihood of being in residential care in 2001. Subsequent analysis of the LS confirmed the association between living in rented accommodation in 2001 and being unmarried at the end of that decade, with being in an institution at end of that decade. ${ }^{19}$ Finally, recent analysis of the BHPS $^{20}$ has shown that older age and poor health are key determinants of moving into residential care in the UK.

The impact of an individual's socioeconomic status on their risk of moving into long-term care has also been explored in the context of England and Wales, drawing a strong link between such indicators as housing tenure, reflecting low socioeconomic resources and the transition into residential care. For example, Glaser $e t a l^{21}$ used data from the LS from 1971, 1981 and 1991 in order to analyse factors associated with older women's move into co-residential (or 'supported') private households or residential care, and found that owner occupiers were more likely than tenants to move into co-residential private households. Socioeconomic predictors indicating low socioeconomic status have been found to be equally important for men and women, with living in rented accommodation and in a household without access to a car in 1971, resulting in a 35-45\% higher risk of being in an institution in $1991 .^{16}$ The 'protective' effect of owning one's home as opposed to renting accommodation with regard to moving into long-term care accommodation has also been highlighted elsewhere in the literature. ${ }^{22}$ Also drawing on the LS, Grundy and Jitlal ${ }^{18}$ found that living in rented accommodation in 1991, which is associated with a lower socioeconomic status, increased an individual's risk of being in residential care 10 years later. Finally, Evandrou et $a l^{20}$ found that having been a hospital inpatient for 15 days or more in the previous year remained an important predictor of moving into residential care even after controlling for health and sociodemographic factors.

Our paper draws on such existing research in order to conceptualise moves into sheltered accommodation as being affected by a wide range of factors such as the demographic, health and socioeconomic characteristics of the older person, as well as policy-related factors which include the receipt of state support (see figure 1).

\section{AIM}

The overall aim of this study is to understand the predictors of moving into sheltered accommodation in later life, focusing on factors which have been used in the past to examine transitions into other types of long-term care, specifically residential care. As such, the study aims to bridge the gap between existing literature on one's transition into residential care with such transitions into sheltered accommodation. The research question addressed in this paper is: What are the determinants of transitions into sheltered accommodation in later life?

\section{METHODS}

This paper employs waves 2-18 of the BHPS (1993-2008) to study transitions into sheltered accommodation in England and Wales. The BHPS is a nationally representative longitudinal survey of households in the UK, collecting individual and household-level information on demographic and socioeconomic characteristics, health, care and well-being, finances and other indicators. ${ }^{23}$ An assessment of quality and attrition in waves $1-13$ of the BHPS sample ${ }^{24}$ concluded that the BHPS data do not present substantial bias resulting from attrition. The analytical sample focused on people aged 65 and over in England and Wales, living in private housing at the first observation and observed at two consecutive points $(\mathrm{N}=23589)$. Individuals with these characteristics were identified sequentially

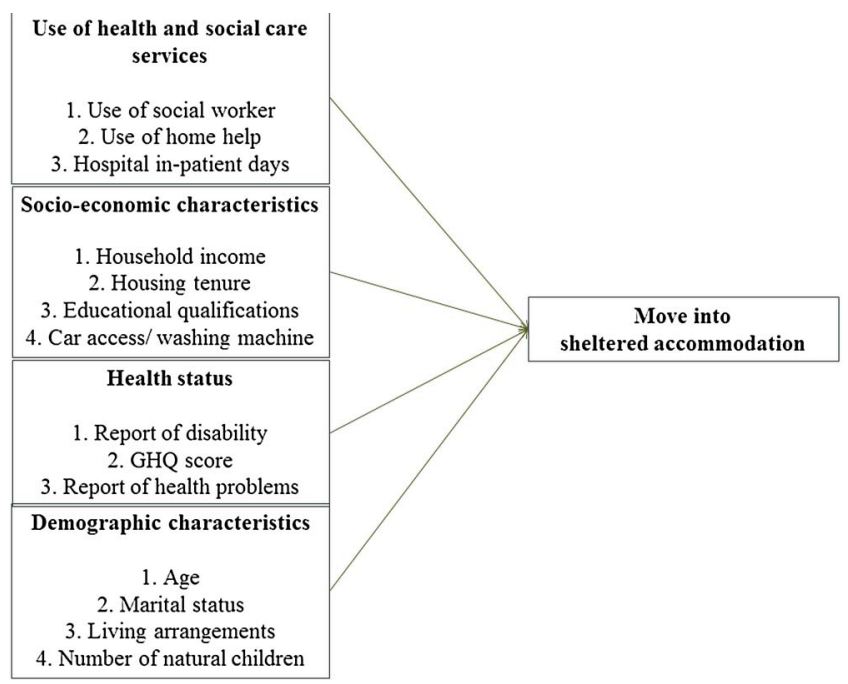

Figure 1 Conceptualising moves into sheltered accommodation. GHQ, General Health Questionnaire. 
in each pair of waves, and waves $2-18$ were stacked to create one large data set. The model selection process relied on manual forward selection starting from a model including only an intercept, and adding the explanatory variables in thematic groups thereafter (demographic; health status and use of care services; socioeconomic; interaction terms). The model selection process stops when further significant improvement in fit cannot be reached. Likelihood ratio tests, using the change in the L2 goodness-of-fit statistic, were used to test the significance of terms and interactions, and to inform the decisions about their inclusion in the next stage of the model selection process. Robust SEs were obtained to control for the non-independence of observations due to the longitudinal nature of the data, and finally SPSS V.22 and STATA V.12 were used for the data set construction and the analysis.

The outcome variable was the respondent's transition into sheltered accommodation at the second point of observation $(\mathrm{t} 1)$, and all explanatory variables were collected at time $0(\mathrm{t} 0)$, allowing for the investigation of an individual's circumstances prior to the transition. Key indicators of status change between t0 and t 1 were constructed (eg, change in use of social worker between $\mathrm{t} 0$ and $\mathrm{t} 1$ ), and interaction terms between the respondents' use of services such as home help, and their age and number of days spent in the hospital as an inpatient, were also included in order to test for the relationship between age and indicators of need among older people.

The inclusion of data set wave controls for changes in the risk of moving into sheltered accommodation over time, while the inclusion of region takes into account the geographical dispersion of unpaid care provision which can affect transitions into sheltered accommodation. ${ }^{25}$ Demographic characteristics include the respondent's sex; the number of natural ever born children as potential sources of informal support; household type controlling for the effect of living alone or with other persons; and marital status-controlling for the 'protective' effect of having a spouse in later life. ${ }^{18}$ The respondent's health status is measured through the change in health status between t0 and t1; one's General Health Questionnaire (GHQ) score and disability status at $t 0$; the change in these two indicators between $t 0$ and $t 1$; and the presence and number of health problems such as hearing or blood pressure between t0 and t1. The use of formal care services by the respondents was also included in the analysis focusing on: the number of visits to the general practitioner (GP) in the past 12 months; hospital inpatient days at $t 0$; and the use of services at $t 0$ such as from a health visitor, home help, meals on wheels or a social worker, as well as the change in such use of services between $t 0$ and $t 1$. Socioeconomic and financial characteristics, which are proxies for an individual's socioeconomic status, ${ }^{26}$ are measured at to and include the respondent's: highest educational qualification, occupational social class based on last occupation, access to a car/van; housing tenure; central heating; having a washing machine; subjective financial status; equivalised household income in quintiles; and receipt of attendance allowance, income support, disability allowance or second pension (includes a pension from an ex-employer, spouse's ex-employer, private pension or annuity).

\section{RESULTS}

\section{Descriptive results}

Based on the analysis of the BHPS, between 1992 and 2008 in England and Wales, 175 individuals moved from their private home into sheltered accommodation. The proportion of individuals in the data set making the move decreased during this

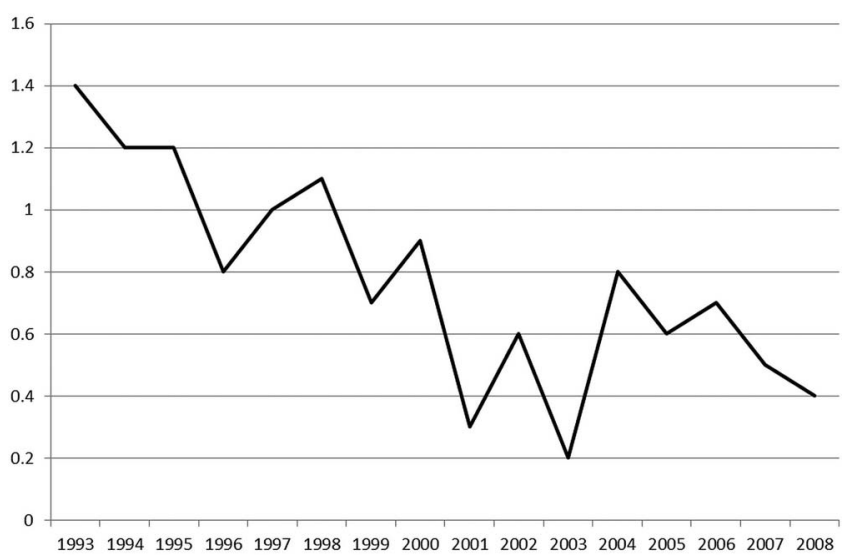

Figure 2 Percentage of older people moving into sheltered accommodation, England and Wales, 1992/1993-2008. Source: British Household Panel Survey (BHPS), waves 1-18, unweighted data. Note: for example, in 1993, 8 out of 573 older persons moved into sheltered accommodation (1.39\% of older people in that year).

period, reflecting the changes in the policy context of longterm care discussed in the Background section of this paper (figure 2).

The descriptive analysis (table 1) showed significant relationships between the move into sheltered accommodation and key demographic characteristics, such as age, marital status and one's household type, and table 2 presents the distributions within the group of older people who moved into sheltered accommodation, and those who did not. Variables reflecting an

Table 1 Variables associated with an older person's move into sheltered accommodation (bivariate analysis)

\begin{tabular}{|c|c|}
\hline Variables & $\begin{array}{l}\chi^{2} \text { statistics } \\
\text { (degrees of freedom) }\end{array}$ \\
\hline Age group & $104.485^{* * *}(4)$ \\
\hline Sex & $6.260 *(1)$ \\
\hline Marital status & $61.466^{* * *}(3)$ \\
\hline Household type & $85.947^{* * *}(1)$ \\
\hline Region & $26.048 * * *(3)$ \\
\hline Visits to GP in past 12 months & $15.708^{* *}(5)$ \\
\hline GHQ score & $22.409^{* * *}(4)$ \\
\hline Change in GHQ score between t0 and t1 & $14.978 * *(2)$ \\
\hline Use of health visitor & $26.235^{* * *}(1)$ \\
\hline Change in use of health visitor between t0 and $\mathrm{t} 1$ & $21.817^{* * *}(2)$ \\
\hline Use of home help & $42.803^{* * *}(1)$ \\
\hline Use of social worker & $9.715^{* *}(1)$ \\
\hline Use of meals on wheels & $25.697^{* * *}(1)$ \\
\hline Education & $16.326^{* * *}(2)$ \\
\hline Washing machine & $443.709 * * *(1)$ \\
\hline Housing tenure & $263.200 * * *(3)$ \\
\hline Access to car & $87.901 * * *(2)$ \\
\hline Household income quintile & $16.842^{* *}(5)$ \\
\hline Receipt of attendance allowance & $26.488^{* * *}(1)$ \\
\hline Receipt of income support & $46.219 * * *(1)$ \\
\hline Wave & $30.182 *(15)$ \\
\hline \multicolumn{2}{|c|}{$\begin{array}{l}\text { Source: BHPS, waves } 2-18 \text {. } \\
\text { Note: categories of missing responses were included in the analysis but are not } \\
\text { shown above. All variables measured at t0 unless otherwise stated. } \\
{ }^{* * *} p<0.001 ;{ }^{* *} p<0.01 ;{ }^{*} p<0.05 \text {. } \\
\text { BHPS, British Household Panel Survey; GHQ, General Health Questionnaire; GP, } \\
\text { general practitioner. }\end{array}$} \\
\hline
\end{tabular}


Table 2 Distribution of statistically significant variables among movers into sheltered accommodation and non-movers (bivariate analysis)

\begin{tabular}{|c|c|c|}
\hline & $\begin{array}{l}\text { Percentage of } \\
\text { movers }\end{array}$ & $\begin{array}{l}\text { Percentage of } \\
\text { non-movers }\end{array}$ \\
\hline \multicolumn{3}{|l|}{ Demographic } \\
\hline \multicolumn{3}{|l|}{ Sex } \\
\hline Men & 34.3 & 43.7 \\
\hline Women & 65.7 & 56.3 \\
\hline \multicolumn{3}{|l|}{ Age group } \\
\hline $65-74$ & 27.4 & 58.7 \\
\hline $75-79$ & 25.7 & 21.1 \\
\hline $80-84$ & 24.6 & 13.1 \\
\hline $85-89$ & 17.7 & 5.6 \\
\hline 90 and over & 4.6 & 1.5 \\
\hline \multicolumn{3}{|l|}{ Marital status } \\
\hline Married or living with spouse & 29.7 & 57.2 \\
\hline Widowed & 57.1 & 31.4 \\
\hline Divorced or separated & 4.6 & 5.3 \\
\hline Single never married & 8.6 & 6 \\
\hline \multicolumn{3}{|l|}{ Household type } \\
\hline Living with others & 29.7 & 63.6 \\
\hline Living alone & 70.3 & 36.4 \\
\hline \multicolumn{3}{|l|}{ Region } \\
\hline London & 5.7 & 6.9 \\
\hline South of England & 37.7 & 22.5 \\
\hline Rest of England and Channel Islands & 44.6 & 49.4 \\
\hline Wales & 12 & 21.2 \\
\hline \multicolumn{3}{|l|}{ Socioeconomic } \\
\hline \multicolumn{3}{|l|}{ Education } \\
\hline No qualifications & 68 & 52.7 \\
\hline None of mentioned or O/A levels & 16 & 24.8 \\
\hline $\begin{array}{l}\text { Degree, teaching, nursing or other higher } \\
\text { qualification }\end{array}$ & 16 & 22.4 \\
\hline \multicolumn{3}{|l|}{ Washing machine } \\
\hline Yes & 37.7 & 88.8 \\
\hline No & 62.3 & 11.2 \\
\hline \multicolumn{3}{|l|}{ Housing tenure } \\
\hline Own outright & 18.9 & 66.3 \\
\hline Own with mortgage & 1.7 & 6.3 \\
\hline $\begin{array}{l}\text { Rented from Local Authority or Housing } \\
\text { Association }\end{array}$ & 74.3 & 22.8 \\
\hline Rented privately & 5.1 & 4.6 \\
\hline \multicolumn{3}{|l|}{ Access to car } \\
\hline Yes & 17.1 & 51.8 \\
\hline No & 50.3 & 26 \\
\hline Do not drive & 32.6 & 22.2 \\
\hline \multicolumn{3}{|l|}{ Receipt of income support } \\
\hline Yes & 21.7 & 7.8 \\
\hline No & 78.3 & 92.2 \\
\hline \multicolumn{3}{|l|}{ Receipt of attendance allowance } \\
\hline Yes & 20 & 8.9 \\
\hline No & 80 & 98.1 \\
\hline \multicolumn{3}{|l|}{ Household income quintile } \\
\hline First quintile (richest) & 34.3 & 23.3 \\
\hline Second quintile & 28 & 23.2 \\
\hline Third quintile & 12.6 & 15.5 \\
\hline Fourth quintile & 9.7 & 10.6 \\
\hline Fifth quintile (poorest) & 5.7 & 8.4 \\
\hline \multicolumn{3}{|l|}{ Health } \\
\hline \multicolumn{3}{|l|}{ GHQ score } \\
\hline $0-3$ & 4 & 4.5 \\
\hline
\end{tabular}

Table 2 Continued

\begin{tabular}{|c|c|c|}
\hline & $\begin{array}{l}\text { Percentage of } \\
\text { movers }\end{array}$ & $\begin{array}{l}\text { Percentage of } \\
\text { non-movers }\end{array}$ \\
\hline $4-6$ & 10.9 & 6.2 \\
\hline $7-9$ & 18.3 & 13 \\
\hline $10-12$ & 59.4 & 72.9 \\
\hline \multicolumn{3}{|c|}{ Change in $\mathrm{GHQ}$ between $\mathrm{t} 0$ and $\mathrm{t} 1$} \\
\hline Score decreased & 17.1 & 13.1 \\
\hline Otherwise & 70.3 & 80.6 \\
\hline \multicolumn{3}{|l|}{ Use of health visitor } \\
\hline Yes & 21.7 & 10 \\
\hline No & 78.3 & 90 \\
\hline \multicolumn{3}{|l|}{ Use of home help } \\
\hline Yes & 16.6 & 5.3 \\
\hline No & 83.4 & 94.7 \\
\hline \multicolumn{3}{|c|}{ Use of meals on wheels } \\
\hline Yes & 6.9 & 1.9 \\
\hline No & 93.1 & 98.1 \\
\hline \multicolumn{3}{|l|}{ Use of social worker } \\
\hline Yes & 7.4 & 3.2 \\
\hline No & 92.6 & 96.8 \\
\hline \multicolumn{3}{|c|}{ Change in health visitor } \\
\hline Started use & 15.4 & 6.6 \\
\hline Otherwise & 84.6 & 93.4 \\
\hline \multicolumn{3}{|c|}{ Visits to GP in past 12 months } \\
\hline None & 8 & 15.7 \\
\hline $1-2$ & 33.7 & 31.5 \\
\hline $3-5$ & 22.9 & 26.8 \\
\hline $6-10$ & 21.7 & 14.1 \\
\hline $10+$ & 13.7 & 11.7 \\
\hline
\end{tabular}

Source: BHPS, 1993-2008, authors' calculations, $\mathrm{N}=23589$ (175 movers, 23414 non-movers).

Note: categories of missing responses were included in the analysis but are not shown above. All variables measured at to unless otherwise stated.

BHPS, British Household Panel Survey; GHQ, General Health Questionnaire; GP, general practitioner.

older person's health status and their use of services are significantly associated with moving into sheltered accommodation, for example, one's GHQ score, and their use of services from meals on wheels, a health visitor or a social worker, all measured prior to the respondents' move into such accommodation. In addition to the geographical region, a range of socioeconomic indicators, such as one's education, housing tenure, access to car and having a washing machine, were also associated with their move into sheltered accommodation.

The determinants of moving into sheltered accommodation Transitions into sheltered accommodation were significantly associated with one's age and service use (table 3). Individuals aged 75 and over were more likely to move into sheltered accommodation than those aged below 75 (although the CIs in the ORs between the groups overlapped, indicating that there is not much difference between the age groups over age 75 ). Individuals who had visited the GP between six and nine times in the past 12 months were more likely to make such a move than those who had made no such visits (OR 2.97), as were those who had started using a health visitor's services between t0 and t. Interestingly, although health was significant in the bivariate analysis, no health variables remained significant in the final multivariate analysis once other factors had been taken into account (see online supplementary tables S4 and S5). More 
Table 3 Determinants of moving into sheltered accommodation (final model)

\begin{tabular}{|c|c|c|c|}
\hline & Number of persons aged $65+$ & $\begin{array}{l}\text { Percentage of transitions } \\
\text { into sheltered accommodation } \\
\text { between t } 0 \text { and } t 1\end{array}$ & OR (Cls at $95 \%$ level) \\
\hline \multicolumn{4}{|l|}{ Age group } \\
\hline 65-74 (ref) & 13798 & 0.3 & 1 \\
\hline $75-79$ & 4985 & 0.9 & $2.02^{* *}(1.33$ to 3.07$)$ \\
\hline $80-84$ & 3119 & 1.4 & $2.43^{* * *}(1.58$ to 3.73$)$ \\
\hline $85-89$ & 1336 & 2.3 & $3.05^{* * *}(1.88$ to 4.95$)$ \\
\hline $90+$ & 351 & 2.3 & $2.64^{*}(1.19$ to 5.81$)$ \\
\hline \multicolumn{4}{|l|}{ Visits to GP in past 12 months } \\
\hline None (ref) & 3687 & 0.4 & 1 \\
\hline $1-2$ & 7439 & 0.8 & $1.99 *(1.10$ to 3.61$)$ \\
\hline $3-5$ & 6322 & 0.6 & 1.56 (0.84 to 2.91$)$ \\
\hline $6-9$ & 3351 & 1.1 & $2.97^{* *}(1.58$ to 5.57$)$ \\
\hline 10 or more & 2758 & 0.9 & $1.73(0.88$ to 3.41$)$ \\
\hline \multicolumn{4}{|l|}{ Change in use of health visitor between t0 and t1 } \\
\hline Otherwise (ref) & 22010 & 0.7 & 1 \\
\hline Started using health visitor & 1572 & 1.7 & $1.79 *$ (1.16 to 2.77$)$ \\
\hline \multicolumn{4}{|l|}{ Housing tenure } \\
\hline Owned outright (ref) & 15546 & 0.2 & 1 \\
\hline Owned with mortgage & 1473 & 0.2 & $1.44(0.44$ to 4.75$)$ \\
\hline Local authority or housing association rented & 5476 & 2.4 & $6.86^{* * *}(4.56$ to 10.33$)$ \\
\hline Privately rented/rented from employer/other rented & 1094 & 0.8 & 1.51 (0.70 to 3.26$)$ \\
\hline \multicolumn{4}{|l|}{ Washing machine } \\
\hline Yes (ref) & 20862 & 0.3 & 1 \\
\hline No & 2727 & 4 & $5.72^{* * *}(4.07$ to 8.04$)$ \\
\hline \multicolumn{4}{|l|}{ Region } \\
\hline London (ref) & 1632 & 0.6 & 1 \\
\hline South of England & 5325 & 1.2 & $3.21^{* *}(1.62$ to 6.36$)$ \\
\hline Rest of England and Channel Islands & 11649 & 0.7 & 1.31 (0.67 to 2.57 ) \\
\hline Wales & 4983 & 0.4 & $1.42(0.65$ to 3.07$)$ \\
\hline Log Likelihood Ratio & & & 1621.433 \\
\hline
\end{tabular}

variables relating to service use were also statistically significant in the initial models shown in online supplementary tables S4 and S5 but were not significant in the final model. Socioeconomic indicators were found to be important predictors of moving into sheltered accommodation. The odds of moving into sheltered accommodation among respondents renting their house from a local authority or housing association were 6.13 times the odds among those who owned their home outright, while those with no washing machine were more likely than those with one to move into sheltered accommodation. Finally, there was also a regional effect on an individual's odds of moving into sheltered accommodation, with the odds among individuals in the South of England being three times the odds among those in London.

\section{DISCUSSION}

Previous literature has discussed the characteristics associated with older persons' transitions into residential care, highlighting particular demographic (eg, being female), health (eg, reporting poor health) and socioeconomic (eg, indicating lower socioeconomic status) characteristics as predictors of moving into residential care. For example, Evandrou et $a l^{20}$ found that older age, poor health and being widowed or single are strongly associated with moves into residential care. By contrast, this paper examined predictors associated with an older person's transition into sheltered accommodation. The results suggest that the move into sheltered accommodation is associated with a complex set of factors and a unique 'pathway' into long-term care in later life. Indicators of an older person's socioeconomic circumstances appear to have strong effect on the risk of such transitions, although demographic characteristics and geographical region are also important. The key difference between moving into sheltered accommodation and other types of long-term care, which indicates a unique pathway for the former, appears to be the complex influence of a range of factors. ${ }^{20}$ For example, variables indicating contact with health professionals (visits to the GP and the start of use of health visitor's services), and factors reflecting low socioeconomic status (not having a washing machine and living in socially rented accommodation prior to the transition) were found to be significant predictors of moves into sheltered accommodation. Such a set of factors may indicate that contact with key gatekeepers is important in facilitating older people's move to this type of accommodation. It is noteworthy that more factors associated with an individual's health status, such as the use of a health visitor's services and the report of disability, were significant in the initial models (see online supplementary tables S4 and S5), suggesting that we cannot ignore the relative contribution of such factors in transitions into sheltered accommodation. 
As such, the factors associated with the risk of moving into sheltered accommodation may be linked to the characteristics of this type of accommodation, as well as the likely relationship between age and health status of individuals at the time of making the transition. Although moves into sheltered accommodation are more likely to take place at a later part of old age, they may be experienced by individuals whose health status does not result in a critical demand for entering long-term care, but who may still receive support for particular tasks. In addition, places in sheltered accommodation may also be allocated for renting by local councils to individuals of lower socioeconomic status, which could explain the importance of indicators in the model which reflect a lower socioeconomic status. Such indicators may also be reflective of the extent to which individuals make use of housing (and other) wealth before moving into sheltered accommodation, or in order to move into such accommodation. ${ }^{27}$ Finally, our analysis did not show an impact of one's living arrangements (household type) or marital status on the risk of moving into sheltered accommodation, which contrasts with previous findings on the 'protective' effect of marriage in later life. ${ }^{18}$ In this sense, the move into sheltered accommodation may be a joint choice for couples at an earlier point of their old age, when the move into long-term care is not necessitated by one partner's critical care need.

The paper has certain limitations which should be considered when interpreting the findings of the analysis. First, the BHPS data set offers information about older people's move into 'long-term stay' institutions; however, older people who were considered too frail to interview have been excluded from the sample, therefore the analysis is likely to be underestimating the proportion of older people moving into such institutions. Second, the data set does not include any information on the receipt of informal care from relatives or friends, which is a key determinant of the 'residual' of an older person's need for longterm care. Variables indicating an individual's demographic characteristics and living arrangements, such as their de facto marital status and whether they have children or not, may partly contribute to our assumption of informal care availability; however, informal care receipt remains an unknown factor in our analysis. An additional limitation is the fact that the analysis does not take step-children or adopted children into account, which could also increase the availability of informal care. Similarly, the analysis only focuses on individual moves, rather than the moves of couples. Equally important to take into account is the fact that moves into sheltered accommodation are a rare event, a fact which we have tried to address by using a paired wave approach in our analysis. Finally, due to the nature of the data, we cannot establish causal links but only associations between the response and the explanatory variables.

\section{CONCLUSION}

The results of this paper have implications both for the design of social care provision for older people and for older people's quality of life during periods when their housing arrangements change. Such results need to be contextualised in recent policy debates in Britain, which have emphasised the importance of maintaining independence for older people for as long as possible, and promoting greater choice among housing options in later life, which are both value for money and adequate for their health and social care needs. ${ }^{6}$ Overall, the findings suggest that a complex set of demographic and socioeconomic factors, as well as factors reflecting contact with health professionals, are important determinants of moves into sheltered accommodation, indicating that access to this type of housing option may be an option for individuals with limited financial resources who are referred by gatekeepers and who move as part of lifecourse planning. Most sheltered housing for rent is provided by councils and housing associations. ${ }^{28}$ The findings indicate that existing local authority tenants may have greater access to such housing than those in the private sector. Given the beneficial outcomes of sheltered housing in comparison with independent housing in the community, ${ }^{15}$ one implication is that policymakers and planners could consider making such a housing option available to all, so that those most in need can access it, as well as providing incentives to the housing and building sectors to include more lifecourse-sensitive design.

\section{What is already known on this subject}

Previous studies have focused on transitions into residential care however; to date, transitions into sheltered accommodation have not been explored. Such studies have shown that transitions into residential and nursing care are associated with older age, poor health, single marital status and indicators of low socioeconomic status.

\section{What does this study add}

This study uses a nationally representative and longitudinal data set to examine the predictors associated with an older person's move into sheltered accommodation. The results show that such transitions are significantly associated with one's demographic characteristics (age); contact with health professionals (number of visits to general practitioner, start of use of health visitor's services); geographical location (region); and socioeconomic factors (housing tenure, having a washing machine). In addition, the results indicate a unique pathway of transitioning into sheltered accommodation, compared with other types of long-term care accommodation, such as residential care, suggesting that such transitions may be undertaken by individuals who have been in contact with key gatekeepers prior to the move and/or who are already resident in social housing.

Acknowledgements The British Household Panel Study (BHPS) was conducted by the Institute for Social and Economic Research (ISER) at the University of Essex with funding from the ESRC and accessed via the UK Data Archive. The research team gratefully acknowledge the assistance of Dr James Robards and Dr Zhixin Feng in earlier stages of this research.

Contributors This study was conceived and designed by all four authors. OM conducted the preliminary statistical analysis, AV and JF finalised the analysis, and $\mathrm{AV}$ wrote the first draft of the manuscript. All authors contributed to critical revisions of the manuscript and approved the final submitted version.

Funding This research was supported by the Engineering and Physical Sciences Research Council (EPSRC) Care Life Cycle (CLC) Research Programme (grant number EP/H021698/1) and the Economic and Social Research Council (ESRC) Centre for Population Change (CPC) (grant number RES-625-28-0001 and ES/K007394/1) at the University of Southampton.

Competing interests None declared.

Provenance and peer review Not commissioned; externally peer reviewed.

Open Access This is an Open Access article distributed in accordance with the Creative Commons Attribution Non Commercial (CC BY-NC 4.0) license, which permits others to distribute, remix, adapt, build upon this work non-commercially, and license their derivative works on different terms, provided the original work is properly cited and the use is non-commercial. See: http://creativecommons.org/ licenses/by-nc/4.0/ 


\section{REFERENCES}

1 European Commission. Long-term care in the European Union. Luxembourg: Office for Official Publications of the European Communities, 2008.

2 Pickard L, Wittenberg R, Comas-Herrera A, et al. Care by spouses, care by children: projections of informal care for older people in England to 2031. Soc Policy Soc 2007:6:353-66.

3 Office for National Statistics (ONS). Families and households 2001-2011. Statistical bulletin. London: Office for National Statistics, 2012.

4 Office for National Statistics (ONS). Mid-2012 population estimates. Great Britain: estimated resident population by single year of age and sex. London: Office for National Statistics, 2013.

5 Dilnot A, Williams J, Warner N. Fairer care funding. London: The Commission on Funding of Care and Support, 2011.

6 Department of Health. Caring for our future: reforming care and support. London: The Stationery Office, 2012.

7 Netten A. Personal social services. In: Powell M, Bauld L, Clarke K, eds. Social Policy Review 17. Bristol: Policy Press, 2005:85-103.

8 Lewis J, Glennerster H. Implementing the new community care. Buckingham: Open University Press, 1996.

9 National Housing Federation. On the pulse: housing routes to better health outcomes for older people. London: National Housing Federation, 2012.

10 Ferreira M. Housing for older people globally. What are best practices? An ILC Global Alliance Discussion Paper. London: International Longevity Centre, 2013.

11 Challis D, Abendstern M, Clarkson P, et al. Comprehensive assessment of older people with complex care needs: the multi-disciplinarity of the Single Assessment Process in England. Ageing Soc 2010;30:1115-34, 2010.

12 Luppa M, Luck T, Weyerer $\mathrm{S}$, et al. Prediction of institutionalization in the elderly. A systematic review. Age Ageing 2010;39:31-8.

13 Martikainen $P$, Nihtila $E$, Moustgaard $H$. The effects of socioeconomic status and health on transitions in living arrangements and mortality: a longitudinal analysis of elderly Finnish men and women from 1997 to 2002. J Gerontol B Psychol Sci Soc Sci 2008;63:S99-109.

14 McCann M, Grundy E, O'Reilly D. Why is housing tenure associated with a lower risk of admission to a nursing or residential home? Wealth, health and the incentive to keep 'my home'. J Epidemiol Community Health 2012;66:166-9.

15 van Bilsen PM, Hamers JP, Groot W, et al. Sheltered housing compared to independent housing in the community. Scand J Caring Sci 2008;22:265-74.
16 Breeze E, Stafford M. Receipt and giving of help and care. In: Banks J, Lessof C, Nazroo J, Rogers N, Stafford M, Steptoe A. eds. Financial circumstances, health and well-being of the older population in England. The 2008 English Longitudinal Study of Ageing. London: Institute for Fiscal Studies, 2010:348-85.

17 Evandrou M, Falkingham J, Rake K, et al. The dynamics of living arrangements in later life: evidence from the British Household Panel Survey. Popul Trends 2001;105:37-44.

18 Grundy E, Jitlal M. Socio-demographic variations in moves to institutional care 19912001: a record linkage study from England and Wales. Age Ageing 2007;36:424-30.

19 Grundy E. Household transitions and subsequent mortality among older people in England and Wales: trends over three decades. J Epidemiol Community Health 2011;65:353-9.

20 Evandrou M, Falkingham J, Maslovskaya O, et al. The determinants of transitions into residential care in later life in the England and Wales. EPSRC Care Life Cycle Discussion Paper 2. 2015. Southampton: University of Southampton.

21 Glaser K, Grundy E, Lynch K. Transitions to supported environments in England and Wales among elderly widowed and divorced women: the changing balance between co-residence with family and institutional care. J Women Aging 2003;15:107-26; discussion 185-7.

22 Grundy E, Glaser K. Trends in, and transitions to, institutional residence among older people in England and Wales: 1971 to 1991. J Epidemiol Community Health 1997:51:531-40.

23 Taylor MF, Brice J, Buck N, et al. British Household Panel Survey user manual volume A: introduction, technical report and appendices. Colchester: University of Essex, 2010.

24 Lynn P. Quality profile: British Household Panel Survey. Version 2.0: waves 1 to 13: 1991-2003. Institute for Social and Economic Research. Colchester: University of Essex, 2006.

25 Office for National Statistics (ONS). 2011 Census analysis: unpaid care in England and Wales, 2011 and comparison with 2001. Newport: Office for National Statistics, 2013.

26 Evandrou M. Social inequalities in later life: the socio-economic position of older people from ethnic minority groups in Britain. Popul Trends 2000;101:11-18.

27 Van Groenou MB, Glaser K, Tomassini C, et al. Socio-economic status differences in older people's use of informal and formal help: a comparison of four European countries. Ageing Soc 2006;26:745-66.

28 AgeUK. Housing options. London: AgeUK, 2015. 